\title{
INVESTMENT PLATFORMS IN THE INFRASTRUCTURE OF THE FINANCIAL MARKET OF THE RUSSIAN FEDERATION
}

\author{
Elena G. Russkova \\ Volgograd State University, Volgograd, Russian Federation \\ Elena V. Chaykina \\ Sevastopol State University, Sevastopol, Russian Federation \\ Valery Yu. Chaykin \\ Financial University under the Government of the Russian Federation, Moscow, Russian Federation
}

\begin{abstract}
Today investment platforms are at the stage of formation and development, and they do not occupy an essential share of the financial market. However, digital data processing, automated service provision, availability of financial resources and minimum costs of transaction processing are the factors stimulating market development in the Russian Federation.

The article presents the research results of investment platforms in the Russian Federation. The authors gave a comparative assessment of platforms in the domestic financial market. The article described the problems and prospects of developing crowdfund investments in the Russian Federation. In the analysis of investment platforms the author used general scientific methods, such as comparison, generalization and the logical approach. As a result of the conducted research the author draws the conclusion that the volumes and number of transactions on Russian investment platforms increase. However, this method of capital investment did not reach the level of necessary standards which would give the chance of its universal application.

Moreover, this way of project financing implies essential risks which are much higher in the Russian Federation, than in the European countries. The lack of the platform activity state regulation and inability to control the platform at the Smart System level is the paramount reason of that risks.
\end{abstract}

Key words: investment platform, crowdfunding, crowdlending, crowdinvesting, loan.

Citation. Russkova E.G., Chaykina E.V., Chaykin V.Yu. Investment Platforms in the Infrastructure of the Financial Market of the Russian Federation. Vestnik Volgogradskogo gosudarstvennogo universiteta. Seriya 3, Ekonomika. Ekologiya [Science Journal of Volgograd State University. Global Economic System], 2019, vol. 21,

\section{ИНВЕСТИЦИОННЫЕ ПЛАТФОРМЫ В ИНФРАСТРУКТУРЕ ФИНАНСОВОГО РЫНКА РОССИЙСКОЙ ФЕДЕРАЦИИ}

\author{
Елена Геннадиевна Русскова
}

Волгоградский государственный университет, г. Волгоград, Российская Федерация

Елена Васильевна Чайкина

Севастопольский государственный университет, г. Севастополь, Российская Федерация

Валерий Юрьевич Чайкин

Финансовый университет при Правительстве РФ, г. Москва, Российская Федерация 
Аннотация. В настоящее время в России инвестиционные платформы находятся на этапе формирования и развития и не занимают существенной доли финансового рынка, но цифровая обработка данных, автоматизированное предоставление услуг, доступность финансовых ресурсов и минимальные затраты на обработку транзакций являются факторами, стимулирующими его развитие.

В статье представлены результаты исследования инвестиционных платформ в Российской Федерации. Авторы дали сравнительную оценку платформам на отечественном финансовом рынке. В статье описаны проблемы и перспективы развития краудфинансирования в России. При анализе инвестиционных платформ были использованы общенаучные методы познания, такие как сравнение, обобщение и логический подход. По итогам проведенного исследования сделан вывод о том, что объемы и количество сделок на инвестиционных российских платформах растут. Однако данный инструмент финансового рынка не достиг того уровня развития, который дал бы возможность его повсеместного применения.

Более того, данный способ финансирования проектов несет с собой существенные риски, которые в Российской Федерации значительно выше, чем в европейских странах. Первостепенной причиной является отсутствие государственного регулирования деятельности платформ и неспособность контролировать платформу на уровне Smart-систем.

Ключевые слова: инвестиционная платформа, краудфандинг, краудлендинг, краудинвестинг, займ.

Цитирование. Русскова Е. Г., Чайкина Е. В., Чайкин В. Ю. Инвестиционные платформы в инфраструктуре финансового рынка Российской Федерации // Вестник Волгоградского государственного университета. Серия 3, Экономика. Экология. - 2019. - Т. 21, № 2. - С. 90-98. - DOI: https://doi.org/10.15688/jvolsu3.2019.2.8

\section{Введение}

В РФ на сегодняшний день активно реализуется национальная программа «Цифровая экономика», которая затрагивает все сегменты экономики, в том числе и финансовый рынок России. В законопроекте от 10 октября 2018 г. «Основные направления развития финансового рынка Российской Федерации на период 2019-2021 годов» большое внимание уделяется применению и развитию цифровых технологий для предоставления финансовых услуг. В проекте указывается, что «...цифровизация - это давно назревший процесс качественного изменения принципов работы финансового рынка, не требующего обязательного физического перемещения или потребления ценностей, а основанного на хранении и учете информации, которая легко преобразуется, накапливается и обрабатывается с помощью все более мощных средств вычислительной техники». Инвестиционные платформы (краудфандинг) как раз и относятся к цифровым технологиям для предоставления финансовых услуг.

\section{Результаты и обсуждение}

ЦБ РФ разработал проект Федерального закона № 419090-7 «О привлечении инвестиций с использованием инвестиционных платформ», где дается определение инвестиционной плат- форме, устанавливаются правила, предъявляемые к платформе, способы осуществления инвестиций посредством платформы и другие важные моменты, регулирующие деятельность инвестиционных платформ. Согласно проекту инвестиционная платформа - информационная система в информационно-телекоммуникационной сети «Интернет», используемая для заключения с применением информационных технологий и технических средств этой инвестиционной платформы договоров, на основании которых привлекаются инвестиции, и доступная также в качестве мобильного приложения.

На сегодняшний день инвестиционные платформы обладают потенциалом стать альтернативной формой финансирования, дополнительным источником привлечения заемных средств, в том числе для малого и среднего бизнеса. В дорожной карте Банка России по развитию финансирования субъектов малого и среднего предпринимательства указаны проблемы, часть из которых можно решить с помощью инвестиционных платформ, а именно: увеличить объемы кредитования, повысить доступность финансовых ресурсов, в том числе для начинающих предпринимателей и высокотехнологичных компаний, повысить скорость обслуживания, снизить операционные издержки при кредитовании субъектов МСП и упростить механизм взаимодействия участников. Также инвестиционные платформы не имеют ограничений по территориальному признаку, и поэтому в 


\section{УПРАВЛЕНИЕ ЭКОНОМИЧЕСКИМ РАЗВИТИЕМ}

процесс могут быть привлечены лица из самых отдаленных регионов, что важно для России с учетом ее масштабов и особенностей климата. Платформы при правильно организованной работе могут обеспечить наличие кредитных ресурсов для реализации проектов с высоким уровнем риска.

В зарубежных странах аналогом инвестиционных платформ являются краудфандинговые площадки, они получили широкое распространение. Краудфандинг - форма финансирования проектов через привлечение малых денежных сумм от большого количества интернет-пользователей. Новые модели исключают посредников, и их можно классифицировать «в зависимости от того, что именно предлагается взамен потраченного ресурса: donation-based (фандрайзинг); reward-based (предпродажи); investment-based (краудинвестинг). Фандрайзинг - это просто желание поддержать проект, reward-based краудфандинг - экономия на дисконтированной цене будущего продукта, а краудинвестинг - доходность от вложений» [Направления развития ..., 2018].
В России привлечение инвестиций с использованием инвестиционных платформ (краудфандинг) развивается не так активно, как в Европе. Темпы роста существенно медленнее мировых. По данным Центрального банка России с 2015 г. объем краудфинансирования растет (рис. 1), и за первые три месяца 2018 г. он превысил 2,33 млрд руб., что в 1,6 раза больше, чем за аналогичный период предыдущего года. Рост объема привлеченных инвестиций происходит за счет сегмента В2В (выдача займов одним юридическим лицом другому юридическому лицу) и сегмента Р2В (выдача займов юридическому лицу или индивидуальному предпринимателю физическим лицом).

Первые краудфандинговые площадки в РФ начали функционировать с 2008 г. со стартом проекта «Kroogi.ni» - интернет-площадки для музыкантов, работающей по схеме «заплати сколько можешь» [Попова и др., 2017]. В 2011 г. появился сервис взаимного кредитования «Вдолг.ру», который «был создан при поддержке коллекторского агентства ФАСП и известного российского аналитичес-

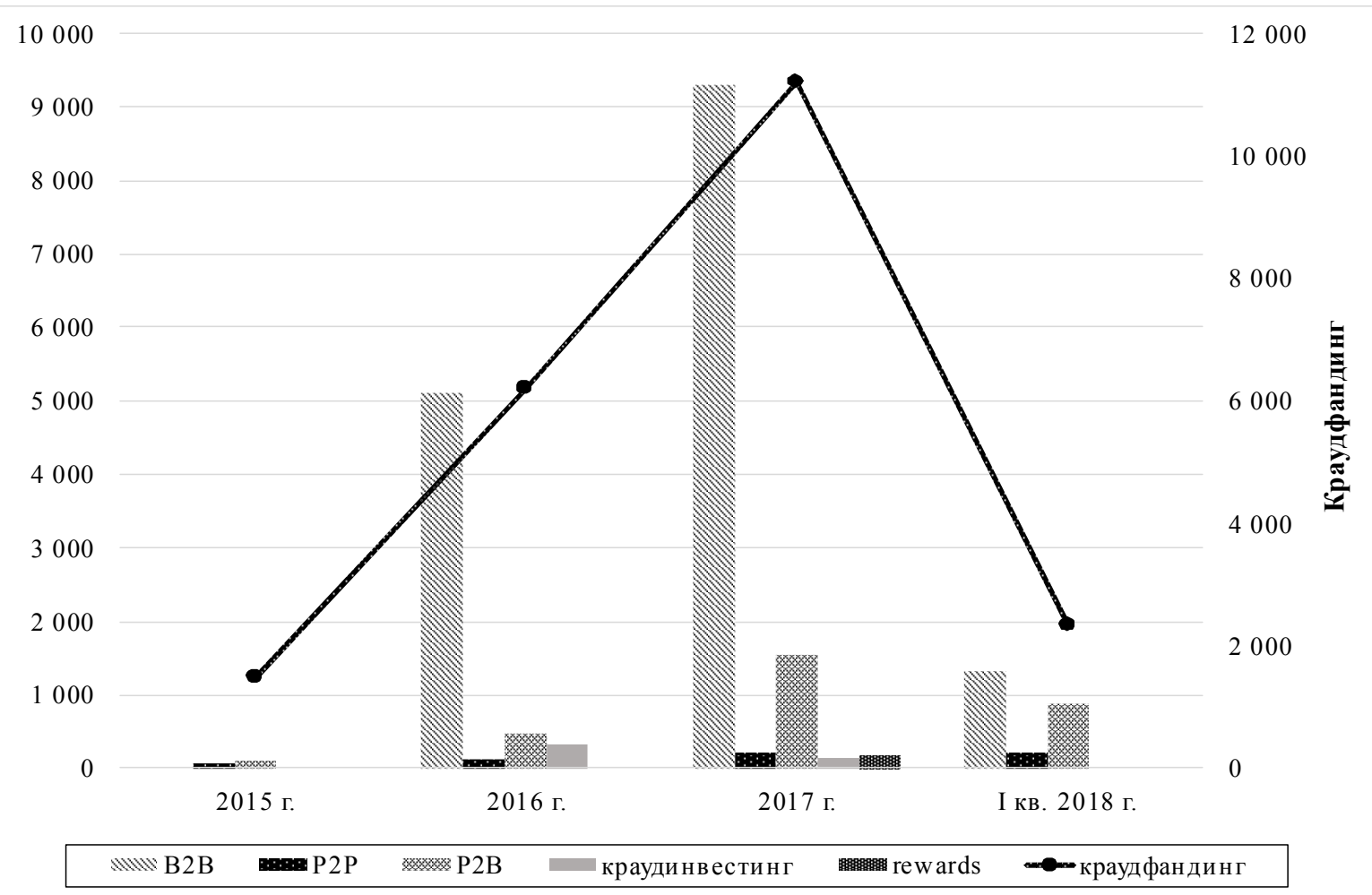

Рис. 1. Инвестиционные платформы в РФ

Примечание. Составлено авторами по данным ЦБ РФ: [Объем рынка краудфандинга ...]. 
кого портала “Banki.ru”» [Самые крупные ...]. В 2012 г. произошел запуск площадок «Boomstarter», «Planeta.ru», «Город Денег», «Loanberry», «С миру по нитке» и др., а в 2016 г. заработала платформа «Constart». На сегодняшний день в нашей стране конкурируют свыше 25 площадок.

На начало 2019 г. по данным Ассоциации операторов инвестиционных платформ в РФ осуществляют свою деятельность 19 площадок в форме краудлендинг (в рамках Р2P,
B2B), 3 площадки в форме reward и 3 площадки в форме краудинвестинг.

Сравним и рассмотрим действующие платформы по видам предоставляемых услуг.

К краудлендинговым платформам (инвестирования за проценты по займу) относятся: Fundico, Пирс, Карма, SimplyFi, Поток и Альфа-Банк, SMARTUP, Финам, Money Friends, Penenza, Город Денег, StartTrack, FAN.MONEY, МодульДеньги, АтомИнвест, Loanberry, Zaimoteka, Bezbanka (табл. 1) и др.

\section{Основные краудлендинговые платформы в РФ}

Таблица 1

\begin{tabular}{|c|c|c|}
\hline $\begin{array}{c}\text { Название, } \\
\text { дата создания }\end{array}$ & Краткая характеристика & Условия работы с инвесторами, заемщиками, создателями проектов \\
\hline $\begin{array}{l}\text { Fundico, } \\
2015 \text { г. } \\
\text { (https://www. } \\
\text { fundico.ru) }\end{array}$ & $\begin{array}{l}\text { Сервис по получению } \\
\text { и предоставлению по- } \\
\text { требительских займов } \\
\text { (Р2P, В2В) }\end{array}$ & $\begin{array}{l}\text { Платформа проводит оценку платежеспособности заемщика. } \\
\text { Процентные ставки по займам: Рейтинг А - не кредитуются; } \\
\text { Рейтинг В - 19,5-22,93 \%; Рейтинг C - 22,94-30,7 \%; Рейтинг D - не } \\
\text { кредитуются; Рейтинг UD - не кредитуются. } \\
\text { Комиссии платформы: } \\
\text { - расходы заемщика за завершение сделки, разовая комиссия 4,29 \% } \\
\text { от суммы (на этот процент уменьшается получаемая на счет заемщи- } \\
\text { ка сумма займа); } \\
\text { - расходы заемщика на реструктуризацию (увеличение срока займа) } \\
39000 \text { рублей за каждый договор; } \\
\text { - кредитор оплачивает платформе сервисную комиссию } 1 \text { \% годовых } \\
\text { от инвестированных в займы средств }\end{array}$ \\
\hline $\begin{array}{l}\text { Город Денег, } \\
2012 \text { г. } \\
\text { (https://townmoney. } \\
\text { ru/lp/loan/wcapital) }\end{array}$ & $\begin{array}{l}\text { Сервис по получению } \\
\text { и предоставлению по- } \\
\text { требительских займов } \\
\text { (Р2Р, В2В), специали- } \\
\text { зируется на кредито- } \\
\text { вании малого и сред- } \\
\text { него бизнеса }\end{array}$ & $\begin{array}{l}\text { «Услуги платформы: } \\
\text { - проверка документов заемщика; } \\
\text { - финансовый анализ и присвоение кредитного рейтинга; } \\
\text { - сопровождение сделки до ее завершения; } \\
\text { - подготовка договоров; } \\
\text { - работа с просроченной задолженностью. } \\
\text { Сумма займа: от } 10000 \text { руб. до } 10 \text { млн руб. } \\
\text { Сумма инвестирования: от } 100000 \text { руб. } \\
\text { Срок займа: от } 6 \text { мес. Обеспечение: поручительство и залоги, обес- } \\
\text { печивающие гарантии возвратности. Комиссия платформы «Город } \\
\text { Денег» составляет от 1\%» [Платформа «Город Денег»] }\end{array}$ \\
\hline $\begin{array}{l}\text { Fingooroo, } \\
2014 \text { г. } \\
\text { (http://fingooroo.ru) }\end{array}$ & 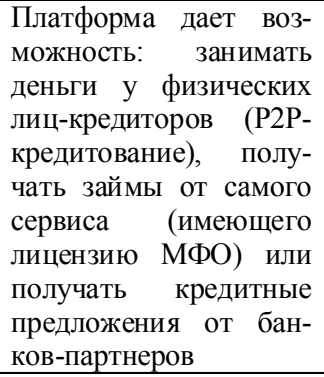 & $\begin{array}{l}\text { Сервис работает полностью дистанционно и использует неквалифи- } \\
\text { цированную ЭЦП (электронно-цифровая подпись), которая реализо- } \\
\text { вана через одноразовые sms, высылаемые на верифицированный те- } \\
\text { лефон клиента. } \\
\text { Платформа взымает с заемщика комиссию в размере } 5 \text { \% от суммы } \\
\text { сделки }\end{array}$ \\
\hline $\begin{array}{l}\text { Loanberry, } \\
2012 \text { г. } \\
\text { (https://www. } \\
\text { loanberry.ru) }\end{array}$ & $\begin{array}{l}\text { Платформа по полу- } \\
\text { чению и предоставле- } \\
\text { нию потребительских } \\
\text { займов от одного фи- } \\
\text { зического лица дру- } \\
\text { гому }\end{array}$ & $\begin{array}{l}\text { Средняя сумма займов на Loanberry.ru составляет } 40000 \text { рублей, в то } \\
\text { время как диапазон заявок варьируется от } 20000 \text { до } 500000 \text { рублей. } \\
\text { Заем предоставляется на срок от } 3 \text { месяцев до } 3 \text { лет с индивидуаль- } \\
\text { ным графиком погашения. } \\
\text { Комиссия составляет } 10 \% \text { от суммы предоставленных денег и вычи- } \\
\text { тается из них автоматически }\end{array}$ \\
\hline $\begin{array}{l}\text { Bezbanka, } \\
2011 \Gamma . \\
\text { (https://bez- } \\
\text { banka.ru) }\end{array}$ & $\begin{array}{l}\text { Платформа по получе- } \\
\text { нию и предоставлению } \\
\text { потребительских зай- } \\
\text { мов от одного физиче- } \\
\text { ского лица другому }\end{array}$ & $\begin{array}{l}\text { Репутация участников системы «БезБанка» определяется по показате- } \\
\text { лям: «уровень доверия» и «деловая активность». } \\
\text { К преимуществам кредитования относится возможность срочно полу- } \\
\text { чить ссуду, самостоятельно выбрать ставку по процентам и срок зай- } \\
\text { ма, отсутствие денежных затрат на юридическое оформление сделки, } \\
\text { а также возможность проверить заемщика посредством обращения в } \\
\text { Национальное бюро кредитных историй }\end{array}$ \\
\hline
\end{tabular}

Примечание. Составлено авторами. 
С момента появления инвестиционных платформ наиболее популярными являются краудлендинговые. Количество пользователей, зарегистрировавшихся на вышеуказанных платформах (табл. 1), превышает 500 тыс. человек. B Loanberry на начало 2019 г. зарегистрировано более 90 тыс. человек, а число зарегистрированных пользователей на портале «Bezbanka.ru» превысило 100 тысяч.

В конце 2018 г. на площадке «Город Денег» лица, привлекающие инвестиции, получили 300 млн рублей. Полученные деньги были использованы для реализации более 260 бизнес-проектов. На платформе «Fingooroo» в этот же период времени было оформлено 5888 договоров между участниками инвестиционной платформы, привлечено 374 млн рублей и реализовано 1849 успешных проектов. В начале 2019 г. заемщики и кредиторы системы взаимного кредитования «БезБанка» заключили бо- лее 49 тысяч успешных сделок на сумму более 365 млн рублей. Из приведенных данных видно, что платформы достаточно активны и на сегодняшний день планируют развивать свой сервис в сторону автоматизации с использованием зарубежного опыта. Например, платформа «Fingooroo» будет брать займы одновременно у нескольких кредиторов, тем самым значительно снижая риски для последних. Именно такая схема народного кредитования (краудлендинга) обеспечила взрывной рост данного сегмента в мире. В настоящее время полные аналоги такого сервиса в России отсутствуют.

В России краудинвестинг (инвестирования за долю в проекте) - самый «молодой» сегмент отрасли. Акционерный краудфандинг (краудинвестинг) представлен платформами: StartTrack, IPOboard, FUTURORUS, MUPIO, CONSTART (табл. 2).

Основные краудинвестинговые платформы в РФ

Таблица 2

\begin{tabular}{|c|c|c|}
\hline $\begin{array}{c}\text { Название, } \\
\text { дата создания }\end{array}$ & Краткая характеристика & Условия работы с инвесторами, заемщиками, создателями проектов \\
\hline $\begin{array}{l}\text { StartTrack, } \\
2013 \text { г. } \\
\text { (https://starttrack.ru) }\end{array}$ & $\begin{array}{l}\text { Платформа позволяет } \\
\text { заключать следующие } \\
\text { виды инвестиционных } \\
\text { сделок: } \\
\text { - купля-продажа до- } \\
\text { лей в уставном капи- } \\
\text { тале компании; } \\
\text { - купля-продажа ак- } \\
\text { ций и облигаций; } \\
\text { - инвестиции по дого- } \\
\text { вору конвертируемого } \\
\text { займа; } \\
\text { - инвестиции по дого- } \\
\text { вору займа }\end{array}$ & $\begin{array}{l}\text { «Минимальная сумма займа от } 10 \text { млн рублей. } \\
\text { Первоначальная средняя ставка по займу } 20-25 \% \text { годовых. } \\
\text { Минимальная сумма инвестиций } 100 \text { тыс. рублей» [Платформа } \\
\text { StartTrack] }\end{array}$ \\
\hline $\begin{array}{l}\text { IPOboard, } 2011 \text { г. } \\
\text { (http://www.ipoboar } \\
\text { d.ru) }\end{array}$ & $\begin{array}{lr}\text { Платформа } & \text { позволяет } \\
\text { привлекать } \quad \text { капитал } \\
\text { непубличных } \\
\text { циннова- } \\
\text { (не старше } 3-4 \text { лет) }\end{array}$ & $\begin{array}{l}\text { Компании могут выставлять доли от 5-10 \% и привлекать до 2-3 млн } \\
\text { долл. США. } \\
\text { Платформа предлагает: } \\
\text { - организацию и сопровождение сделок; } \\
\text { - прямой доступ к полной информации о перспективных инноваци- } \\
\text { онных проектах, прошедших предварительную экспертизу }\end{array}$ \\
\hline $\begin{array}{l}\text { SIMEX, } 2015 \text { г. } \\
\text { (https://simex.global/ } \\
\mathrm{ru})\end{array}$ & $\begin{array}{l}\text { Платформа для обме- } \\
\text { на цифровыми акти- } \\
\text { вами и инвестиций в } \\
\text { ICO проекты }\end{array}$ & $\begin{array}{l}\text { Возможность получить доход: } \\
\text { - путем приобретения инвестиционных долей бизнес-проектов с по- } \\
\text { следующим получением дивидендов; } \\
\text { - посредством привлечения новых инвесторов (партнеров) на биржу } \\
\text { и получения комиссионных начислений в размере от } 0,5 \text { до } 20 \text { \% с их } \\
\text { первичных покупок инвест. долей; } \\
\text { - за счет спекулятивной торговли долями бизнес-проектов в разделе } \\
\text { «Торги» на официальном сайте платформы, где покупка инвест. долей } \\
\text { считается вторичной, - за эти действия партнерские начисления не } \\
\text { предусмотрены. } \\
\text { Минимальная сумма инвестиций в каждом проекте индивидуальна, за- } \\
\text { висит от стоимости одной доли (средняя цена от } 100 \text { до } 1000 \text { рублей). } \\
\text { Доходность: } 1-25 \% \text { в месяц. } \\
\text { Срок инвестиций: от } 30 \text { дней }\end{array}$ \\
\hline
\end{tabular}

Примечание. Составлено авторами. 
На начало 2019 г. в системе «IPOboard» зарегистрированы 142 компании и 223 инвестора. Платформа «StartTrack», созданная в 2013 г. при поддержке Фонда развития интернет-инициатив, осуществила 22 проекта, а количество привлеченных средств составило 325,6 млн рублей. На примере данных, предоставленных этой платформой, видно, что объем основных видов сделок в сегменте бизнес-финансирования составил: $10 \%$-инвестиции в капитал (1,04 млрд руб.) и $90 \%$ инвестиции по договорам займа (2,53 млрд руб.) [Богомолова]. Представленные цифры свидетельствуют о том, что краудинвестинг слабо развивается и занимает малый объем операций на платформах. Поэтому с целью увеличения объема совершаемых сделок в 2018 г. «краудфандинговая платформа "Planeta" и краудинвестинговая площадка "StartTrack" объединились, чтобы выработать механизм поточного привлечения финансирования для стартапов. При получении от автора идеи заявки на создание или инвестирование проекта модераторы площадок, оценивая бизнес и его финансовые потребности, будут опре- делять платформы - краудфандинг или краудинвестинг» [Клещева, 2017].

Что касается основных направлений инвестиций в краудинвестинге, то ими являются оптовая и розничная торговля (рис. 2).

К инвестиционным платформам, осуществляющим свою деятельность в формах reward (привлечение инвестиций за вознаграждение), относятся: Planeta.ru, Crowd republic, Boomstarter (см. табл. 3) и др.

Социальный краудфандинг также набирает обороты с появлением таких платформ, как Boomstarter, Планета.py, С миру по нитке, Dobro.mail.ru, Благотворительный интернет-фонд Помоги.Орг. Основной задачей их деятельности является сбор пожертвований на благотворительные цели, в том числе на социально-медицинские нужды. На начало 2019 г. платформа «Boomstarter» собрала средств на сумму 374 млн рублей, осуществила 1852 успешных проекта, в которых приняло участие 201 тыс. человек. По утверждению основателей платформы «Планета» за 5 лет существования через нее привлечено более 700 млн рублей и успешно завершено более 2,5 тыс. краудфандинговых проектов.

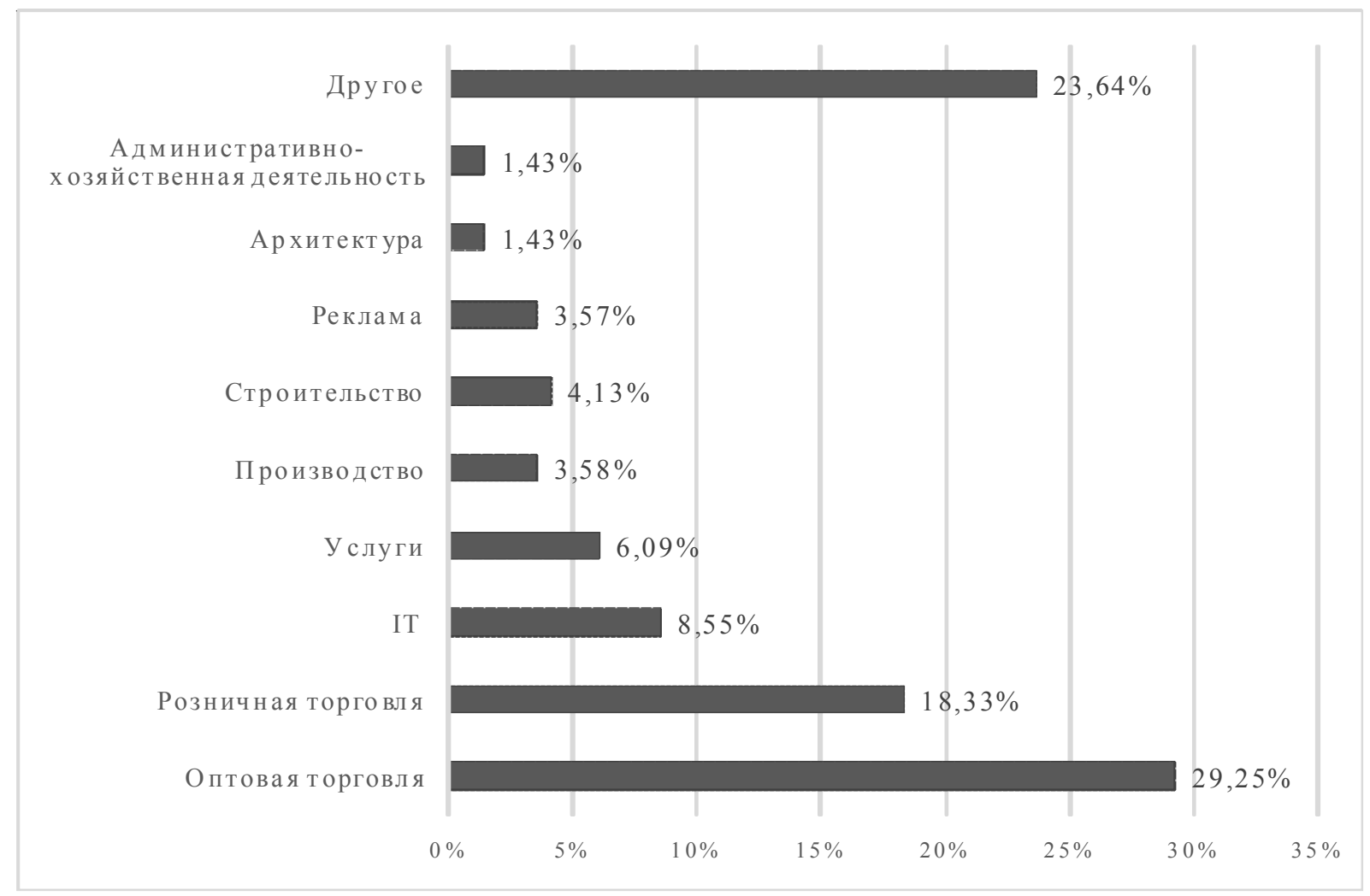

Рис. 2. Инвестиции в капитал через краудфандинговые платформы

Примечание. Составлено авторами по: [Богомолова]. 


\section{Основные краудфандинг Rewards-платформы}

\begin{tabular}{|c|c|c|}
\hline $\begin{array}{c}\text { Название, } \\
\text { дата создания }\end{array}$ & Краткая характеристика & Условия работы с инвесторами, заемщиками, создателями проектов \\
\hline $\begin{array}{l}\text { Planeta.ru, } 2012 \text { г. } \\
\text { (https://planeta.ru) }\end{array}$ & $\begin{array}{l}\text { На платформе после } \\
\text { регистрации любой } \\
\text { желающий может соз- } \\
\text { дать проект и собрать } \\
\text { средства на социаль- } \\
\text { ное, образовательное } \\
\text { или благотворитель- } \\
\text { ное направление }\end{array}$ & $\begin{array}{l}\text { Комиссия «Планеты» составляет } 5 \text { \% от привлеченной суммы в слу- } \\
\text { чае успеха проекта и } 10 \% \text {, если кампания привлекла } 50-99 \text { \% от за- } \\
\text { явленной цели финансирования. } \\
\text { Кроме того, } 5 \% \text { от собранной суммы перечисляется в пользу пла- } \\
\text { тежных систем. } \\
\text { Платформа не взимает комиссию с благотворительных проектов. } \\
\text { Проект может быть продлен, но не более одного раза и не дольше, } \\
\text { чем на изначальный срок финансирования }\end{array}$ \\
\hline $\begin{array}{l}\text { Boomstarter, } 2012 \text { г. } \\
\text { (http://boomstarter.ru) }\end{array}$ & $\begin{array}{l}\text { На платформе прини- } \\
\text { маются проекты в } \\
20 \text { категориях: бизнес, } \\
\text { технологии, крипто- } \\
\text { валюты, туризм и др., } \\
\text { а также можно купить } \\
\text { подарок коллективно } \\
\text { (краудгифтинг) }\end{array}$ & $\begin{array}{l}\text { Комиссия площадки: } \\
\text { - для краудфандинга в проектах } 5 \text { \%; } \\
\text { - для краудгифтинга - процент плавающий и взымается с магазина. } \\
\text { «Размещая свой проект на Воотstarter, автор сохраняет за собой все } \\
\text { права на собственность, но при этом все данные о проекте остаются } \\
\text { общедоступными и после завершения финансирования не могут } \\
\text { быть изменены или удалены. } \\
\text { Для потенциально успешных проектов предусмотрен институт кура- } \\
\text { торства: порядка } 30 \text { кураторов - это партнеры в СМИ, как отрасле- } \\
\text { вые, так и просто общие, которые помогают информировать людей о } \\
\text { проекте при помощи свох медиа-ресурсов» [Платформа } \\
\text { Воomstarter] } \\
\end{array}$ \\
\hline
\end{tabular}

Примечание. Составлено авторами.

В России, как и за рубежом, происходит смешивание разных моделей на одной платформе: в начале работы платформа практикует одну модель, а затем под влиянием рынка другую, что позволяет работать с компаниями на разных этапах развития. В 2016 г. появилась платформа «Constart», которая объединяет краудфандинг, краудинвестинг и краудхантинг - инвестирование знаний и опыта за вознаграждение или долю.

Деятельность российских платформ осуществляется на самостоятельно разработанных интернет-ресурсах и идентична деятельности многих зарубежных платформ.

Провести статистический анализ платформ достаточно сложно из-за того, что это новая услуга на отечественном рынке, которая пока не регулируется и не контролируется государством, а компании - операторы инвестиционной платформы дают минимальную информацию о своей деятельности и не разглашают ее результаты.

Необходимо отметить, что отечественные краудфандинговые платформы имеют свои особенности: площадки конкурируют как с коммерческими банками, так и с небанковскими финансовыми организациями. Значительным недостатком для клиентов платформ является то, что их инвестиции не застрахованы от рисков и не обеспечены гарантийными возмещениями.

С учетом имеющейся информации можно отметить, что объем аккумулируемых средств инвестиционными платформами остается достаточно низким. Краудфандинг может являться альтернативой банковскому кредитованию для субъектов малого и среднего бизнеса, но сегодня в РФ он получил наибольшее распространение для финансирования благотворительных и социальных проектов. При этом значительная часть проектов, набравших стопроцентный объем финансирования, связана с творческими направлениями, характерными для различных видов искусства (кино, музыка, литература). Популярность символических вознаграждений в некоторых проектах подкрепляет общую тенденцию.

\section{Заключение}

Для дальнейшего развития краудфандинга в России необходимы условия, которые способствовали бы росту доверия к этим инструментам и притоку инвесторов. Инвестиционные платформы не подпадают под прямое регулирование ЦБ России и не сдают отчет- 
ность. Законопроект «О привлечении инвестиций с использованием инвестиционных платформ» находится в стадии разработки. Наличие правовой базы позволит организовать регулирование и осуществлять надзор за деятельностью платформ, что приведет к росту количества потенциальных инвесторов. Развитию краудфандинговых площадок может способствовать наличие большого количества инновационных проектов. Также развитие инвестиционных платформ зависит от осведомленности участников данного рынка, в том числе от информирования СМИ об отечественных проектах. Для России характерна низкая финансовая грамотность населения, более активная часть пользователей современных финансовых технологий проживает преимущественно в крупных городах с высокой плотностью населения. Для того чтобы привлечь инвесторов на платформы, рекомендуется проводить курсы по повышению финансовой грамотности населения, семинары, конференции, связанные с деятельностью платформ, масштабные рекламные кампании и другие маркетинговые мероприятия, которые повысят осведомленность населения о данных услугах.

Таким образом, краудфинансирование основано на цифровой обработке данных и автоматизированном предоставлении услуг. Это дополнительный инструмент привлечения инвестиций, который сегодня встраивается в существующий финансовый рынок РФ.

\section{СПИСОК ЛИТЕРАТУРЫ}

Богомолова, А. Инфографика: как устроен рынок краудинвестинга в России. - Электрон. текстовые дан. - Режим доступа: https:// incrussia.ru/understand/infografika-kakustroen-rynok-kraudinvestinga-v-rossii/ (дата обращения: 01.03.2019). - Загл. с экрана.

Клещева, С. А. Краудфинансирование как инструмент инвестирования инновационного предпринимательства / С. А. Клещева // Экономика и банки. - 2017. - № 2. - С. 40-46.

Направления развития финтеха в России: экспертное мнение Финансового университета / М. А. Эскиндаров [и др.] // Мир новой экономики. 2018. - № 2. - С. 6-23.

Объем рынка краудфандинга в 2017 году увеличился в два раза. - Электрон. текстовые дан. -
Режим доступа: http://www.cbr.ru/press/event/ ?id=1902\#highlight $=$ краудфандинговый \% 7Ссектор\% 7 Crewards (дата обращения: 01.03.2019). - Загл. с экрана.

Платформа «Город Денег». - Электрон. текстовые дан. - Режим доступа: https:/townmoney.ru/lp/ loan/wcapital (дата обращения: 01.03.2019). Загл. с экрана.

Платформа Boomstarter. - Электрон. текстовые дан. - Режим доступа: http://boomstarter.ru/ (дата обращения: 01.03.2019). - Загл. с экрана.

Платформа StartTrack. - Электрон. текстовые дан. Режим доступа: https://starttrack.ru (дата обращения: 01.03.2019). - Загл. с экрана.

Попова, И. В. Использование краудфандинговых платформ в России и за рубежом / И. В. Попова, А. С. Безвесельная // Молодой исследователь Дона. - 2017. - № 6 (9). - С. 182-189.

Самые крупные российские площадки краудфандинга. - Электрон. текстовые дан. - Режим доступа: $\mathrm{http}: / /$ ardma.m/fmaiisy/kraudfanding/ 342-samye-krupnye-rossijskie-ploshchadkikraudfandiiiga (дата обращения: 01.03.2019). Загл. с экрана.

\section{REFERENCES}

Bogomolova A. Infografika: kak ustroyen rynok kraudinvestinga $v$ Rossii [Infographics: how the market of a kraudinvesting in Russia is arranged]. URL: https://incrussia.ru/understand/infografikakak-ustroen-rynok-kraudinvestinga-v-rossii (accessed 1 March 2019).

Kleshcheva S.A. Kraudfinansirovaniye kak instrument investirovaniya innovatsionnogo predprinimatelstva [Kraudfinansirovaniye as a tool of innovative business investment]. Ekonomika i banki [Economy and banks], 2017, no. 2, pp. 40-46.

Eskindarov M.A., et. al. Napravleniya razvitiya fintekha v Rossii: ekspertnoye mneniye Finansovogo universiteta [The directions of the fintech development in Russia: expert opinion of the Financial University]. Mir novoy ekonomiki [World of a new economy], 2018, no. 2, pp. 6-23.

Obem rynka kraudfandinga $v 2017$ godu uvelichilsya $v$ dva raza [The volume of the crowdfunding market doubled in 2017]. URL: http://www.cbr.ru/ press/event/?id=1902\#highlight= crowdfunding $\% 7 \mathrm{C}$ sector $\% 7$ Crewards (accessed 1 March 2019).

Platforma «Gorod Deneg» [Platform «Town of Money»]. URL: https://townmoney.ru/lp/loan/ wcapital (accessed 1 March 2019). 


\section{УПРАВЛЕНИЕ ЭКОНОМИЧЕСКИМ РАЗВИТИЕМ}

Platforma Boomstarter [Platform Boomstarter]. URL: http://boomstarter.ru/ (accessed 1 March 2019).

Platforma StartTrack [Platform StartTrack]. URL: https://starttrack.ru (accessed 1 March 2019).

Popova I.V., Bezveselnaya A.S. Ispolzovaniye kraudfandingovykh platform v Rossii i za rubezhom [Employment of crowdfunding platforms in Russia and abroad]. Molodoy issledovatel Dona [The Don's young researcher], 2017, no. 6 (9), pp. 182-189.

Samyye krupnyye rossiyskiye ploshchadki kraudfanding [The largest Russian platforms of crowd funding]. URL: http://ardma.m/ fmaiisy/kraudfanding/342-samye-krupnyerossijskie-ploshchadki-kraudfandiiiga (accessed 1 March 2019).

\section{Information about the Authors}

Elena G. Russkova, Doctor of Sciences (Economics), Professor, Department of Economic Theory and Economic Policy, Volgograd State University, Prosp. Universitetsky, 100, 400062 Volgograd, Russian Federation, dekan.econom@volsu.ru,https://orcid.org/0000-0002-9392-3642

Elena V. Chaykina, Candidate of Sciences (Economics), Associate Professor, Department of Finance and Credit, Sevastopol State University, Universitetskaya St., 33, 299053 Sevastopol, Russian Federation, lena_chaykina@list.ru, https://orcid.org/0000-0003-4413-3414

Valery Yu. Chaykin, Student, Member of the Free Economic Society of Russia (VEO), Financial University under the Government of the Russian Federation, Leningradsky Prosp., 49, 125993 Moscow, Russian Federation, Valeriy.Chaikin@yandex.ru, https://orcid.org/0000-0001-9146-0544

\section{Информация об авторах}

Елена Геннадиевна Русскова, доктор экономических наук, профессор кафедры экономической теории, мировой и региональной экономики, Волгоградский государственный университет, просп. Университетский, 100, 400062 г. Волгоград, Российская Федерация, dekan.econom@volsu.ru, https://orcid.org/0000-0002-9392-3642

Елена Васильевна Чайкина, кандидат экономических наук, доцент кафедры финансов и кредита, Севастопольский государственный университет, ул. Университетская, 33, 299053 г. Севастополь, Российская Федерация, lena_chaykina@list.ru, https://orcid.org/0000-0003-4413-3414

Валерий Юрьевич Чайкин, студент, член Вольного экономического общества России (ВЭО), Финансовый университет при Правительстве РФ, Ленинградский просп., 49, 125993 г. Москва, Российская Федерация, Valeriy.Chaikin@yandex.ru, https://orcid.org/0000-0001-9146-0544 